\title{
What Autists Can Teach Us about Social Interactions and How Psychoanalytic Treatment Can Contribute to It
}

\author{
Ana Beatriz Freire, Fabio Malcher \\ Psychoanalytic Theory of the Institute of Psychology of The Federal University of the State of Rio de Janeiro \\ (UFRJ) \\ Email: freireanab@hotmail.com
}

Received 13 June 2014; revised 11 July 2014; accepted 8 August 2014

Copyright @ 2014 by authors and Scientific Research Publishing Inc.

This work is licensed under the Creative Commons Attribution International License (CC BY). http://creativecommons.org/licenses/by/4.0/

c) (i) Open Access

\section{Abstract}

This paper aims to bring contributions from psychoanalysis to the debate about autism. We assume that while working with the autistic it is imperative to single out each case and not to seek out a standardized approach, based on a previous knowledge. The therapist oriented by psychoanalysis starts to work from a point of view where stereotyped or seemingly bizarre behaviors are taken as a resource used by the subject to protect himself from the invasion experienced in his relationship with others. The treatment, therefore, would not seek to eliminate such behaviors, but to promote the elaboration, on the autistic part, of a way of his own to belong in the world, as we will be able to follow in the exposition of a clinical case in which the subject makes use of objects in a unique manner to mediate his relationship with the other and promote his social interaction.

\section{Keywords}

\section{Psychoanalysis, Autism, Social Interaction}

\section{Introduction}

The International Epidemiological data indicates an increase of the referred Autistic Spectrum Disorder (Fombonne, 2009). The estimated rate is of one in each 88 births (Center for Disease Control and Prevention, 2012; http://www.cdc.gov/media/releases/2012/p0329_autism_disorder.html), confirming that autism has become one of the most common development disorders (Fombonne, 2009; Newschaffer et al., 2007).

In Brazil, there are few epidemiological studies in child psychiatry and these studies tend to emphasize the description of risk factors (extreme poverty, amongst others. Fleitilich-Bilyk \& Goodman, 2001, Goodman, 
Fleitilich-Bilyk, Patel, \& Goodman, 2007), and of more prevalent pathologies, that can appear in comorbidities with Autistic Spectrum Disorder (classified in a large group of less common disorders), such as anxiety disorders, attention deficit and hyperactivity disorder (Fleitich-Bilyk \& Goodman, 2004). Regarding the research in the field of Autistic Spectrum Disorder, in the First Brazilian Meeting for Research in Autism

(http://www6.ufrgs.br/ebpa2010/http://www6ufrgs.br/ebpa2010/), Fombonne (2010) estimated a prevalence of approximately 500 thousand people with autism nationwide, based on the 2000 Census. Among the few studies on the subject, there is a pilot (Paula Ribeiro, Fombonne, \& Mercadante, 2011) carried out in a Brazilian town, which pointed out a prevalence of approximately $0.3 \%$ amongst citizens, presenting global disorders of development. According to the authors, due to the limited scope of the research, there are no reliable estimates of prevalence in our country yet.

One should be reminded that autism was previously described by Leo Kanner, in 1943, as an "affective contact disorder", characterized by "extreme isolation", which would be repeated by the subject in seemingly automated and repetitive activities (Kanner, 1997).

It is crucial to acknowledge that since that time autism has been clinically diagnosed based on the way the patient relates to the other, and not only by laboratorial organic exams. This is because such disorder presents, as a main clinical feature, the difficulty of the subjects to relate to others, including to the ones who are most involved in their care. In most extreme cases, this struggle to relate to others implies a rigid body posture, a non-addressing look, and no response to calls and questions.

At first, it is possible to clinically confirm that the autistic subject presents a "decided exclusion". That is, when the subject avoids to answer the demands of those around him. Then, begins the difficulties in the achievement of shared speech and an extreme isolation, which will be presented in the so called stereotyped, or bizarre behavior, apparently automatized and meaningless, and in the echolalia, the repetition of words coming from others, but without breaks and without apparent subjectivity of meanings.

Psychoanalysis contributes to this treatment in the measure that it questions in each case, the complications that produced this "encapsulation", helping to locate the particular impasses of the subject. The therapist, when oriented, offering himself as a partner in the elaborations of the autistic subject, in a docile way, regulating his presence in order not to be invasive, can make it possible that the supposed bizarre attitudes of the autist may evolve into inventions of his own. The psychoanalytical treatment is determined so that each subject, in his own unique way, should come out of his isolation and, possibly, create bonds with those around him. We can bet, as therapists, that a "bizarre behavior" can be included in the clinical work and develop into an act of creation that will, in time, produce a unique way of social interaction.

In general, the signs that call for a diagnosis appear around two years of age, when difficulties in speech are evident. However, it is possible for signs of autism to be recognized before that age.

Late diagnosis does not prevent treatment, but the sooner one looks for clinical help, the better. Therefore, decreasing the chances of the child shutting himself out from the world. Usually, in a late treatment, we find bigger complications to remove possible social and affective impasses. Clinical experience has shown that the earlier a child is diagnosed and the signs of the disorder perceived, the greater will be the chances of a good response to the treatment.

In a substantial amount of cases, when parents finally look for a psychoanalytical treatment for their child, it is only after they have been through several ineffective ways of treatment which have not satisfied them. Most of their complaints are that some specialists from several areas seek to treat autism by such techniques that often end up by reinforcing, as a paradox, a greater isolation and by increasing the autistic defenses. Some parents also complain, several times, of a certain "robotization" or automation of their children as a side effect to certain approaches.

We think-based on psychoanalysis-that for a professional to be allowed to "enter" the autistic world, he must take into consideration the subjective world built by the autistic subject. In order to do this, the professional must have a more thorough look at the subject. That is, a view of the subject with his own world. This unique look comes from the very moment of the reception, avoiding a standardized assistance, seeking links with services that will not make him imprisoned in a net where typification (universal of classification) and anonymity prevails.

The main barrier is the common "stereotyped" perception that classifies autism as a deficit disorder, as cognitive deficit, and as a consequence, attaches its manifestations to a disease of an unchanging nature which has no treatment. This tendency points to a pharmacological drug treatment as the only solution, when in reality, there 
is a subject who should be taken into consideration.

Donna Williams, an autist who came out of isolation, gave her testimony, "The best approach is the one which would not sacrifice the individuality and the liberty of the child... The people who helped me most were always the most creative and those who cared less for conventions” (Williams, 1992: p. 290).

Going against an "a priori" knowledge, be it of the meaning, be it of the organic, psychoanalysis bets the autist already presents psychic work in his actions and in the way he presents himself to the world. One is not an autist out of his own will. Autism must be considered from a subjective point of view, a "response" or a radical "defense"-not without extreme consequences—in face of the demands of human life, whether they are internal, of language or culture. All of these domains are marked by the presence of the other. In order to set free from this menacing "defense", it is necessary to conceive the autist as a subject in constant psychic work facing a world he believes to be menacing and invasive. In order to achieve this we need to be partners in their constructions and in their seemingly bizarre and meaningless acts. We should avoid the position of "knowing everything" that is happening with them, a knowledge that has already been given, a priori, for that would reinforce in them their "defense" and their isolation. The autists themselves will teach us the function of their objects and the best way to deal with them. It is through a language that belongs to them that we learn how to deal with them, building, based on their indications, a possible direction to establish a bond with them. The relation to the so called autistic objects, for example, which could be considered as stereotypies to be extirpated with the treatment, are to psychoanalysis, an important issue for the treatment. The particular use that the autistic subject establishes with some objects, repeatedly and consistently, may give the impression that they reinforce the autistic isolation. Both clinical experience and the testimony of some autists that speak, demonstrate, however, the function of some objects as important mediators that allow them to establish their body limits and the exchange with others.

Temple Grandin, a high level autist, became famous worldwide for her work as a biologist. In her book, she states that the so called "obsessions" of autists should be seen as centers of interest and one should "try to steer the interest shown by the autist to the direction of constructive activities." (Grandin, 1997).

In a similar way, we will present the narration of a clinical case, where a young man who is not from a high level, that has been receiving treatment in a public institution since he was a child, managed to find his place among those around him, overcoming his barriers, and somehow, acquiring a certain autonomy allowing him to keep a possible dialog with the ones near to him.

\section{Clinical Case}

In order to focus on the significant role the object may have in autism for mediation between individuals and their surroundings, let us accompany an interesting subjective work developed by Nathan while under analysis. His sessions with his current analyst began when he was 16 years old. He is now 19.

Nathan's mother, upon initial interviews stated that he would usually ask her, "Am I your baby?”, often followed by "Do you love me?". This posture of a "baby" seems to have granted him, until the beginning of puberty, a more stable position among those who surround him. However, that place is becoming less comfortable to him, as he begins to hear repeatedly, both at school and at home, the statement: "you are no longer a child". A reality that is hard to be dealt with. Not being a child any more implies becoming a man, thus taking your place in sexual partnership, something very difficult for Nathan due to his psychic structure, as far as such positioning requires the subjective assumption of castration, which is absent in autism.

Freud's discovery that our body is not given to us for granted (Freud, 1905), and must be constituted along pulsional life experiences since the first cares of infancy, becomes evident in Nathan's body incoordination, and in his difficulty in acquiring a pubescent body. The construction of a body is one of the main tasks he has been accomplishing, being also one that presents struggle due to his structural refusal to castration.

At the beginning of the sessions, Nathan hardly spoke in the first person, and avoided eye contact with the analyst. His speech tends to be fragmented, loose words that refer to his interests, such as music or how to deal with the scenes he creates with the dolls, toys that are available in the session room. Those scenes are often repeated, and Nathan hands the dolls to the analyst, indicating what they should do. At those moments, his speech is clearly more fluent and articulate, uttering complete sentences, with adequate verb tenses, and in a commanding tone.

Nathan's mother refuses his invitations to "play" with the dolls at their home, since she considers it "a child thing”. The analyst does not consider such games as merely childish, or without purpose. Very much on the contrary, he values such resources as a peculiar way by which the subject faces his impasses, a true invention. 
The acting with the use of dolls seems to work for Nathan as a resource capable of mediating his relationship with another person, as well as helping him deal with what generates his conflicts, such as growth and the building of a body.

In playful scenes, the characters are almost always the same, and are clearly divided into children and adults, both groups with well-defined functions. Children repeatedly act in a manner to break rules and social conventions; it is up to the adults to punish such acts, as well as to care for the children, bottle feeding them, providing pacifiers, changing diapers, bathing them, moments when their bodies are in evidence.

The relationship with others, which tends to be marked by an invading note, becomes in this process mediated by the objects. He speaks through the dolls, shifting the place of articulation of speech from himself to the dolls in the act (Maleval, 2012). Whereas Nathan does not answer a great number of questions asked by the analyst, or avoids eye contact, during the scenes with the dolls he promptly answers by each of the characters, which have defined proper names, given by him and always respected. He also indicates what each character should be doing in each scene, besides consenting to look at the analyst before answering him.

At some moments of enacting his play, Nathan expresses joy in the form of exaggerated, uncontrolled movements, a very intense laughter, especially when one of the "children" does anything wrong, as well as when the "adult" applies a punishment or draws a limit, a thing that never fails to occur, with the infallible appearance of a character that represents some law. Both cases are delightful to Nathan, revealing certain precariousness in the establishment of the superego, the instance of the law.

Such relationship of the subject with the dimension of the law reveals that, even without the symbolic establishment of the superego, such question largely occupies his mind, placing great part of his work around this issue, in a repetitive effort to circumscribe some kind of border around this hole. The breaking of the law is present in the lack of limits, both by children with their mischief and by adults with their punishments. Children perform acts which are followed by breaking social bonds, such as taking off their clothes at school, playing ball during classes, fighting for objects, amongst others.

The condition of "being a baby" is articulated in his speech when he mentions "sucking a pacifier", "bottle feeding", "wearing diapers", the kind of personal cares adults more often dispense on children in the scenes of his acting. Nathan's work while undergoing analysis allows the possibility of finding a posture facing others different from that of a baby. That important work takes place in the open angle between the "baby", the subjective standing which has worked for him up to a certain point of his life, but which does not point to social interaction any longer, and the "you are not a child any more" statement that comes from those around him, but which sounds invasive, menacing for him, especially for deriving into a positioning in sexual partnership.

The mediation in his relationship with his surroundings coming from that resource becomes evident when he deals with present issues in his life through his acting. A birthday that is coming, body related problems, such as a cold, or a wound in his foot, are themes that Nathan may include in the "scripts" he builds along his play acting. The dolls celebrate their birthdays, and the choice of the party theme or the presents the character is going to receive is mentioned in the acting. Sometimes a doll appears with a wound in its foot, or with a cold, and the adults take care of it. Sometimes he himself sneezes and says it was one of the dolls.

Along the play acting experience, school is a privileged scenery, and the "teacher" helps the students with their personal hygienic care, bathing them, changing diapers, moments in which the other students try to spy on the naked body and Nathan, with giggles, points at and names the parts of the body , such as "breasts", "nipples", "buttocks, ass". He refers to the genitals as "this" or "here". This erogenous mapping of the body of the dolls also occurs in the ceaseless opportunities when children take off their clothes in improper places, and it seems to be part of an effort on Nathan's part to build a body, a thing that becomes growingly pressing due to the bodily changes he has been experiencing in puberty. We have here the fundamental question of how to appropriate himself of a pubescent body, something that always implies a call to sexual partnership.

After some time, Nathan indicates the difference between the genitals of boys and girls. He picks up a doll that has a small piece of string in the place of the genitals and says "it's from a boy", taking afterwards the doll representing the "father", which has a flat genital area, saying "he has it too". When the analyst asks him about the doll representing a girl, he says "she doesn't have it". When facing the question of the difference between the sexes, Nathan starts from the anatomic difference, and even without fully arriving at the logical difference, supported by the reference to castration, his speech about the flat genitalled doll, stating that "he has it too", reveals a symbolic etching to deal with the matter of sexual partnership. It is essential to highlight that this possibility has been opened to Nathan starting from the singular use he makes of the play acting with the dolls, deal- 
ing with his own body by means of his invention. Nathan's body has been visibly more organized, with a steadier way of walking, a better coordination of movements, and according to his family, with progress in his personal care.

\section{Conclusions}

In conclusion, we emphasize that the autists themselves can show us the function of their objects and the best way to deal with them in order to establish the social bond. It is through their own language that we can learn how to dialogue with them, building, based on their indications, a possible treatment direction. The relation to the so called autistic objects, which could be considered merely as stereotypies, is to psychoanalysis, very important for the treatment.

As seen in the above exposed clinic case, the precariousness of symbolic resources in autism makes working via the object a valuable resource, as we have followed the way Nathan used the dolls to mediate his relationship with his surroundings, as well as to address the issues that afflicted him. The object appears to be capable of promoting articulations between the language and the body of the subject, generating a new way of dealing with others and with his own body.

\section{References}

Fleitilich-Bilyk, B., \& Goodman, R. (2001). Social Factors Associated with Child Mental Healthproblems in Brazil: Crosssectional Survey. BMJ, 323, 599-600.

Fleitilich-Bilyk, B., \& Goodman, R. (2004). Prevalence of Child and Adolescent Psychiatric Disorders in Southeast Brazil. Journal of the American Academyof Child \& Adolescent Psychiatry, 43, 728-734.

Fombonne, É. (2009). Epidemiology of Pervasive Developmental Disorders. Pediatricresearch, 65, 591-598. http://dx.doi.org/10.1203/PDR.0b013e31819e7203

Fombonne, É. (2010). Epidemiology of Autism, Paper presented at the $1^{\underline{0}}$ Encontro Brasileiro para Pesquisa em Autismo, Porto Alegre, Rio Grande do Sul, Brasil.

Freud, S. (1905). Três ensaios sobre a teoria da sexualidade. In Obras psicológicas completas de Sigmund Freud, vol. VII. Rio de Janeiro: Imago, 1972, 121-252.

Goodman, A., Fleitlich-Bilyk, B., Patel, V., \& Goodman, R. (2007). Child, Family, School and Community Risk Factors for Poor Mental Health in Brazilian Schoolchildren. Journal of the American Academy of Child and Adolescent Psychiatry, 46, 448-456. http://dx.doi.org/10.1097/chi.0b013e31803065b5

Grandin, T. (1997). Penserenimages. Paris: O. Jacob.

Kanner, L. (1997). Os distúrbios autísticos do contato afetivo. In ROCHA, Paulina (org.) Autismos. São Paulo: Escuta, 111-170.

Maleval. J. C. (2012). Língua verbosa, língua factual e frases espontâneas nos autistas. In Autismo(s) e atualidade: uma leitura lacaniana. orgs. Alberto Murta, Analícea Calmon e Márcia Rosa. Belo Horizonte: Scriptum, 45-66.

Newschaffer, C. J. et al. (2007). The Epidemiology of Autism Spectrum Disorders. AnnualReviewofPublic Health, 28 , 235-258. http://dx.doi.org/10.1146/annurev.publhealth.28.021406.144007

Paula, C. S., Ribeiro, S. H., Fombonne, E., \& Mercadante, M. T. (2011). Prevalence of Pervasive Developmental Disorder in Brazil: A Pilotstudy. Journal of Autism Development Disorder, 41, 1738-1742.

Williams, D. (1992). Si on me touche, je n'existe plus, Robert Laffont, Paris. 
Scientific Research Publishing (SCIRP) is one of the largest Open Access journal publishers. It is currently publishing more than 200 open access, online, peer-reviewed journals covering a wide range of academic disciplines. SCIRP serves the worldwide academic communities and contributes to the progress and application of science with its publication.

Other selected journals from SCIRP are listed as below. Submit your manuscript to us via either submit@scirp.org or Online Submission Portal.
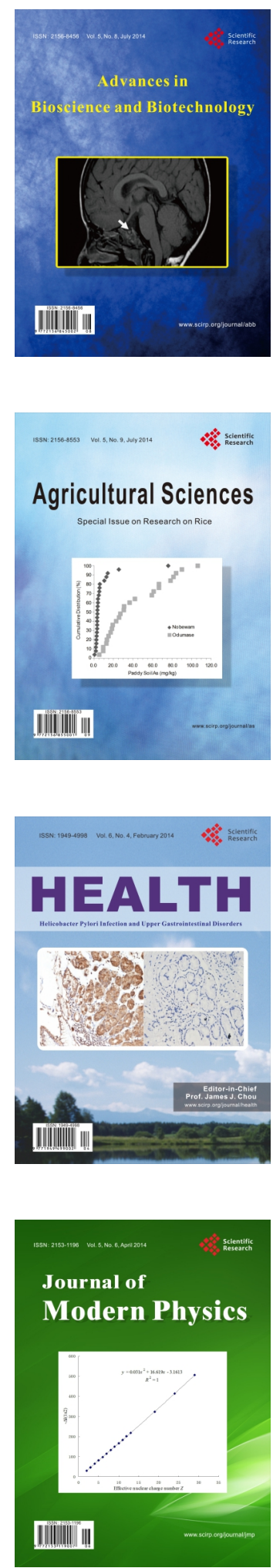
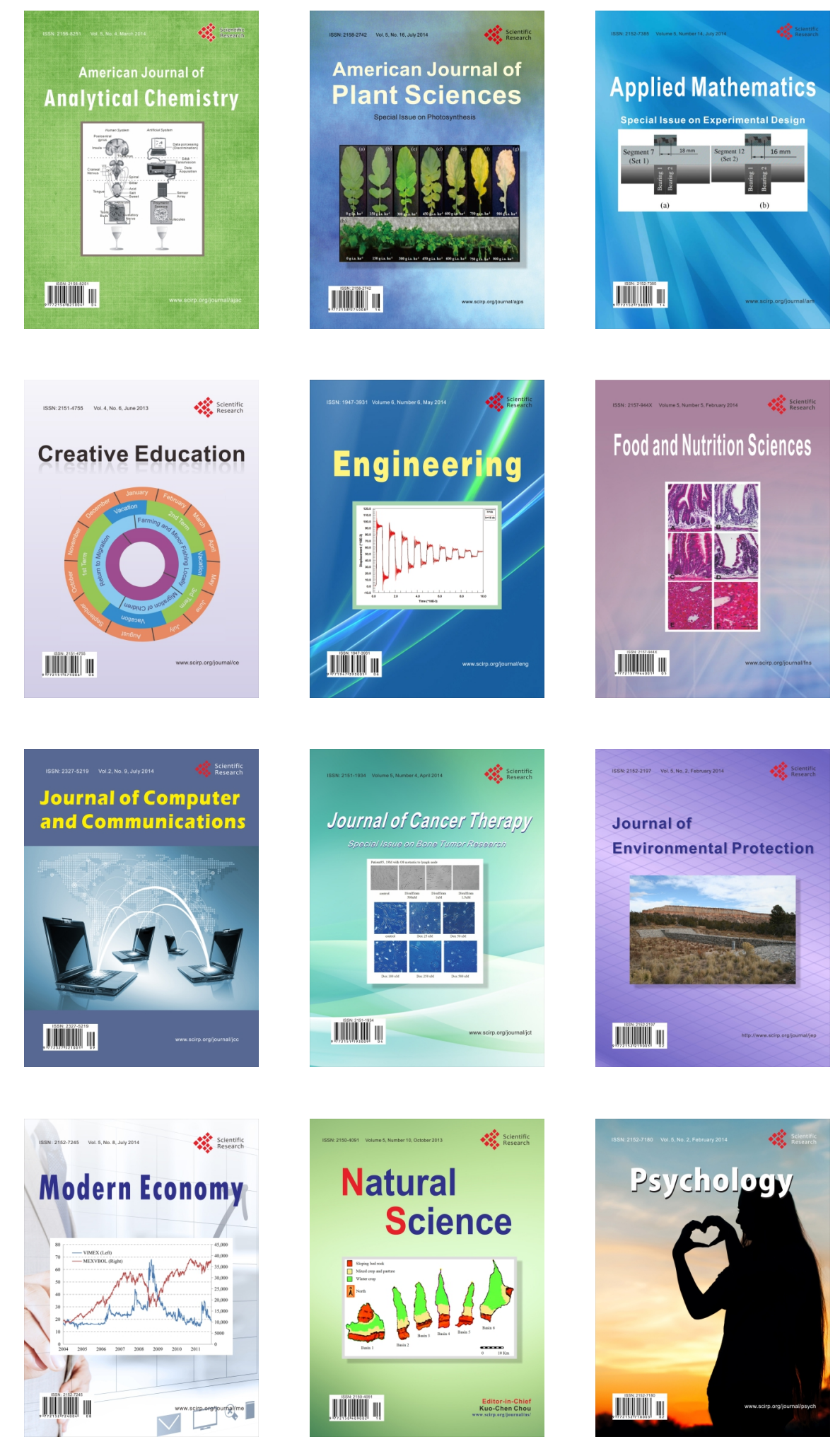